\title{
Editorial
}

\section{Finally we have arrived in a new millennium}

After twelve months in a typical $20^{\text {th }}$ century political style dominated by controversial sanctions within the European Union, a revolution in Serbia and a flareup of war/intifada in Israel - where just recently, during a peaceful moment, a well-received EASD congress attracted about 8000 delegates - the year 2000 has come to an end. The new millennium has finally arrived. It will bring unprecedented social, technical and cultural change. The major forces behind the scenes will be the still uncontrolled rise in the world population, consumerism and ageing populations in industrialised countries as well as new technical and scientific discoveries. Progress in biological science and medical research using embryos, just recently approved in the United Kingdom, will add considerably to the momentum for change. Thus, pluripotent embryonic stem cells could be used not only to replace bone marrow but also to produce spare parts for kidneys, pancreatic beta cells and other tissues.

Problems to be solved will include not only the consequences of environmental pollution, global warming, a potential future energy shortage and an epidemic of life-style dependent chronic diseases but also those resulting from the large ageing populations of the industrialised world. In this context the discussion on euthanasia could gain momentum and the still illegal but tolerated Dutch approach towards voluntary death on demand might become fully accepted in one country of the European Union [1]. It remains to be seen whether the European Union's non-obligatory charter of fundamental rights will halt any developments in this undesirable direction.

In this world to come, diabetes will remain a major health problem and will, in concert with other serious diseases, continue to cause a tremendous amount of suffering. Although our understanding of the disease has come a long way over the last two millennia, since it was defined by Galen as 'diarrhoea per urinas' the aetiologic riddles underlying diabetes are yet to be solved. The diagnostic criteria have constantly been updated and have only recently been recategorised into two main, but heterogenous subgroups, diabetes mellitus Type I and Type II. Against this background diabetes research should be high on the agenda in the years to come both on the national and the international level as so aptly demonstrated by the establishment of a European Foundation for the Study of Diabetes [2].

Since insulin was discovered in 1921 by Banting and Macleod, the treatment of Type I (insulin-dependent) diabetes has become highly successful compared with its state in 1898 . At that time B. Naunyn [3] reported that patients who were younger than 50 years of age at the time of diagnosis could expect to survive only between 3 months and 3 years. Today, a well-treated Type I diabetic patient can expect to have an almost normal life span. Worldwide, however, the problem remains unsolved because the benefits of good diabetes care, requiring insulin as well as appropriate patient education and self care, are only in the reach of patients living in the more affluent societies. Disseminating clinically applicable knowledge and making the necessary resources available worldwide, especially in developing countries, would therefore, be a major breakthrough. A comparable advance would come by replacing destroyed beta cells in insulin-deficient Type I diabetic patients once high-tech methodology, such as tissue engineering and stem-cell transplantation or appropriate gene therapy are available [4]. In contrast, future prevention of beta-cell destruction and thereby of Type I diabetes mellitus seems still to be out of reach as it primarily requires identifying the aetiology [5] and not only that of the persons at risk.

Regrettably, a considerable number of people in the more affluent western societies are not able to cope with the excess caloric supply available, a prob- 
lem exacerbated by physical inactivity and so develop obesity. The clinical manifestation of the obesity/Type II diabetes syndrome is therefore strongly linked to nutritional environmental factors. Among these, free fatty acids play a major part by impairing transmembrane glucose transport and glucose-6-phosphorylation and thereby also glycogen synthesis. The damage caused not only blunts insulin sensitivity but also, if prolonged, glucose-stimulated insulin release. Such 'chronic lipotoxicity' is triggered by post prandial hyperlipidaemia and marked post-absorptive lipolysis from (abdominal) fat stores in patients consuming a high-fat and high-calorie diet over the long term and impairs glucose tolerance and insulin release simultaneously. These processes almost certainly accelerate the manifestation of Type II diabetes and are responsible for the staggering rise in the prevalence of this disease in industrialised countries [6,7].

The inability of a large proportion of the population to cope with a high-caloric food supply results in a considerably greater prevalence of Type II diabetes in affluent societies than in less prosperous societies. Type II diabetes has thus become a scourge growing on a polygenic background of excess high-fat foods and a lack of physical exercise. In contrast to Type I diabetes, Type II diabetes could, however, be prevented in a large segment of the population. This would require public health systems to establish individual incentives to maintain near-normal body weight and an appropriate amount of daily physical exercise. Such incentives could be tax breaks, or even better, a partial annual cash refund of health insurance premiums for those citizens who maintain near-normal body weight and physical strength. Studies to develop such modern public health concepts are to be welcomed. Their results would be published with great interest and delight in Diabetologia.

Once chronic food intoxication is recognised by the public as a major cause of the clinical manifestation of Type II diabetes, preventing and slowing down its progress would be considerably helped. To this end, the food industry could be strongly regulat- ed to produce a tasty diet, low in saturated fat with reduced calorie content, instead of a high-calorie or high-fat junk food. For the food industry to change is all the more advisable since it is possible that in the near future it might have to pay damages similar in scale to those awarded against the tobacco industry today. In contrast, marketing of new oral antidiabetic drugs which dismiss the importance of appetite control will prove ineffective in the prevention of Type II diabetes.

To implement the knowledge we now have on the prevention and therapy of diabetes worldwide will be as great a task as answering the as yet unsolved riddles of diabetes research. Diabetologia looks forward to publishing many exciting and critical scientific reports, which are to be expected in the years to come, and to playing a part in maintaining the health of people in the face of the still heavy burden called diabetes.

Werner K. Waldhäusl

Editor

\section{References}

1. Griffith J, Bood A, Weyers H (1998) Euthanasia and law in the Netherlands. Amsterdam University Press, Amsterdam

2. Nerup J., Halban, P. A. (2000) Sponsor, leader and lobbyist: The European Foundation for the Study of Diabetes (EFSD) and the future of diabetes research in Europe. Diabetologia 43: 1453-1454

3. Naunyn B (1898) Der Diabetes mellitus. Alfred Hölder, Wien, pp 438-459

4. Efrat S (1998) Prospects for gene therapy of insulin dependent diabetes mellitus. Diabetologia 41: 1401-1409

5. Yoon JW (2001) Virus induced diabetes: a model for Diabetes mellitus Type I. Diabetologia 44

6. Waldhäusl WK, Roden M (2000) The effects of free fatty acids on glucose transport and phosphorylation in human skeletal muscle. Current Opinion in Endocrinology and Diabetes 7: 211-216

7. McGarry JD, Dobbins RL (1999) Fatty acids, lipotoxicity and insulin secretion. Diabetologia 42: 128-138 